\title{
Technology Research on Traffic Organization of Wuhan Municipal Engineering Projects Under Construction
}

\author{
Wang Zhiqiang \\ Traffic Research Department \\ Wuhan Transportation Development Strategy Institute \\ Wuhan City, China \\ wzq13@126.com
}

Liu Jin

Traffic Consultation Department

Wuhan Transportation Planning \& Design Co, Ltd

Wuhan City, China

147777492@qq.com

\author{
Zhang Benyong \\ Dean \\ Wuhan Transportation Development Strategy Institute \\ Wuhan City, China \\ Zhangby@wcctpi.com \\ Li Jianzhong \\ Traffic Research Department \\ Wuhan Transportation Development Strategy Institute \\ Wuhan City, China \\ ljzplan@163.com
}

\begin{abstract}
Present Chinese big cities are facing one common problem that road resources have being occupied by the construction of traffic projects. In order to solve the problems of traffic organization during construction properly, this paper put forward the research content and technical principle of municipal engineering projects traffic organization firstly, then suggest a method of traffic organization for viaduct according to the characteristics of the construction period that is divided into three stages (pipelines reconstruction renovation, substructure construction and superstructure construction), which was applied to Traffic organization scheme for construction period of Wuhan Road in Hankou, and it has achieved desired effect. Refer to traffic organization of Wuhan municipal projects under construction, other types of construction projects can be elevated to organize traffic reasonably and keep city traffic common operation, with the consideration of the project characteristics and the actual situation of traffic during construction.
\end{abstract}

Keywords-municipal engineering projects ; under construction ; traffic organization ; traffic impact analysis ; Wuhan city.

\section{INTRODUCTION}

In recent years, Chinese tier one and secondary cities are growing in a period of rapid development of society, economic and traffic, while transportation construction investment is increasing, and concentration of major transport projects are being continued under construction; At the same time, the number of motor vehicles is growing fast, and the conflict between traffic supply and demand have become increasingly prominent, urban traffic " discongest and unblocked " situation is very grim.

A large number of cities including Wuhan city are comprehensively promoting urban construction, such as rails, roads and other large number of municipal traffic projects, so they have been entering the peak period of construction successively. Due to vast occupation of urban road resource, long construction cycle and large traffic impact range have brought severe challenges to normal urban traffic, especially the construction of urban expressway and rail transit construction in the same period increased the difficulty of traffic organization. To the maximum extent to reduce the influence of the construction of urban traffic, and to meet the requirement of normal production and life of travel basically, we must do a good job in the major project construction period transportation organization work.

Formulation of construction period transportation organization of the program should be done to reduce the impact ,protect the travel of goal oriented, coordinate the relationship between traffic and construction according to the macro, medium and micro three levels ,during construction traffic organization control system, with the characteristics of Wuhan engineering projects construction considered, then we put forward relevant traffic organization measures, for the construction of protection during traffic operation to develop a scientific and operable traffic organization scheme.

\section{TRAFFIC ORGANIZATION PRINCIPLE FOR PROJECTS UNDER CONSTRUCTION}

First of all, combined with special circumstance of the municipal engineering construction and the general principles of traffic organization, we summarized several principles which should be satisfied by the municipal engineering project in construction period of traffic organization:

A. Meet the basic requirements of production and life of the city travel.

On the basis of meeting the requirements of construction process of the construction of regional 
security, the surrounding units and residents import requirements.

\section{B. Regional and overall coordination.}

The adjacent engineering construction project should be considered, and different plots should be carried out into a line over the same period. Major traffic affect the construction period staggered principle should be obeyed.

\section{Let the bus and the main direction of traffic flow go first.}

Under tight transportation condition, maintain public transport vehicles and the main direction of traffic priority should be kept, and so the basic requirements of pedestrians.

\section{Use external road or bypass, and build supporting facilities first.}

Make full use of regional road of external shunt and the construction road vehicles should be diverted to all nearby parallel roads to reduce the traffic pressure of the construction area.

\section{E. Tap potential of road under construction to improve its capacity.}

Compact enclosure, saving lane, fine construction of traffic organization that increase road capacity.

\section{F. Obey " $a$ is a" principle in lane occupation.}

Limit the lane construction strictly, arrange the demolition of surrounding buildings reasonably, adjust road cross section, do occupy a lane also built a lane as far as possible.

\section{G. Use effective dissemination, management and safety first}

Increase road construction monitoring and management efforts, equipped with enough traffic police, traffic assistant keepers, ensure that travelers safety and smoothly through the construction area.

\section{THE TECHNOLOGY PROCESS OF TRAFFIC ORGANIZATION DURING CONSTRUCTION}

The process of traffic organization During the construction can be divided into three stages generally: pre-preparation, plan and post-tracking.

Preparation stage: One needs to understand the project construction situation, collect relevant information, documents, and construction area of current situation of traffic survey and analysis and evaluation, thus affecting the construction analysis.

Plan stage: One firstly needs to arrange all the recent construction projects those may have an impact on road traffic within the region in macro coordinate, construction sequence optimization arrangement of research project, with the help of traffic prediction model, also work out a variety of construction period traffic organization scheme, through the comprehensive evaluation, and select the best scheme; then in the medium level, one study and formulate construction traffic organization can adopt the methods and measures; finally in the micro level, one design road construction optimization of organizational, as the project needed for traffic simulation analysis.
Post-tracking stage: It's necessary to grasp the progress of the construction phase, begin traffic survey and dynamic research, analyze the regional traffic changes. Thus, this paper puts forward related suggestions and measures, in order to keep the construction well and city traffic in reasonable operation.

The technology process is shown in Fig 1.

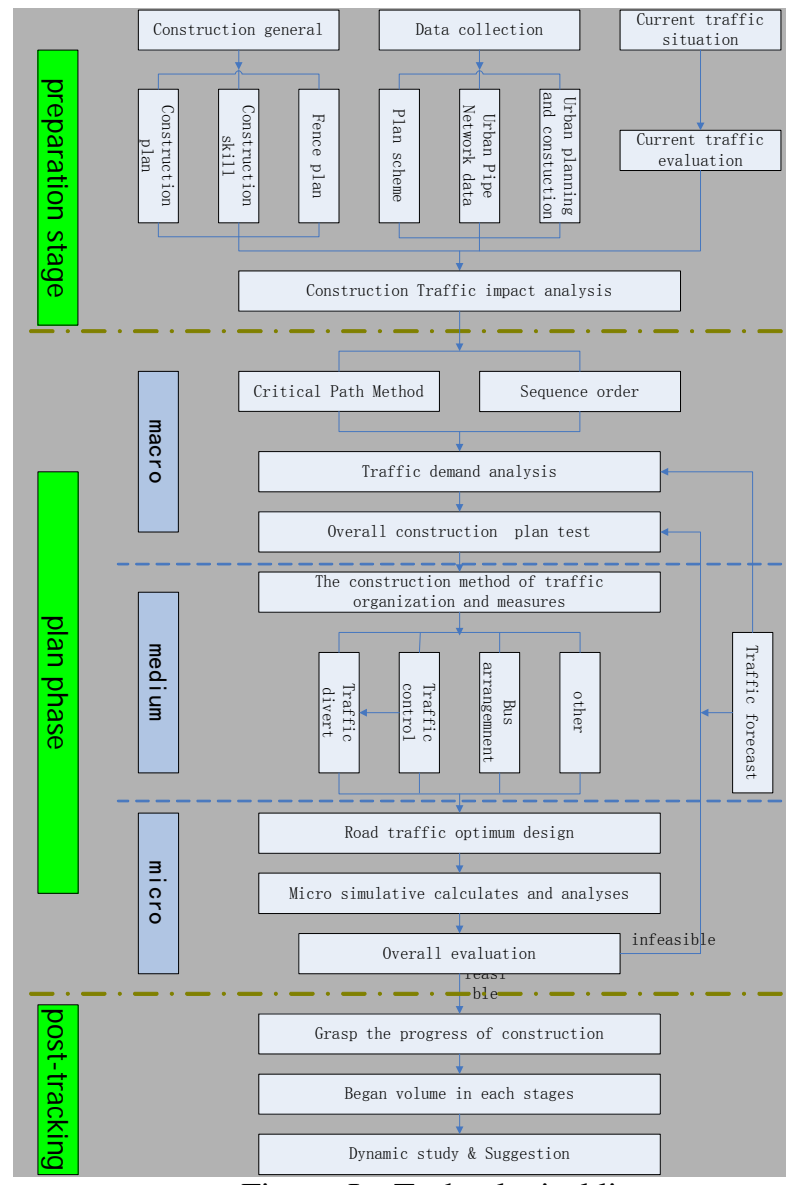

Figure I . Technological line

\section{THE WORKING METHOD OF TRAFFIC ORGANIZATION DURING CONSTRUCTION}

As traffic organization during the construction period is a work filled with theory and practice closely, and it's aimed to solve realistic problems, so people involved must do a good job in field reconnaissance, full investigation, overall coordination and follow-up in real time, dynamic research and field service.

\section{A. On-site reconnaissance}

One needs to look out on-site first before work, and know well the current road section, and traffic volume, bus stations, the buildings along and so on, also should check regional road network at the same time whether there is diversion roads.

\section{B. Full investigation}

Not only traffic volume survey of road under construction, but also similar cases need to be collected. For example, during 2008 Wuhan Chinese Expo, the peak hour traffic volume of Second Changjiang River Bridge in 
Wuhan dropped about 5-6\% after implementation of odd and even number control; In 2009, during the period of implementation of odd and even number control on Wuluo Road and other 5 main Wuchang roads, the peak hour traffic flow of Wuluo Road fell by about $13 \%$.

\section{Multi-coordination}

Construction period transportation organization involves the interests and demands of many aspects, including investment, construction, design, Traffic Management Bureau and pipeline companies, so one do the work needs talk with these relevant units and the department coordination to discuss appropriate construction fence and traffic organization scheme.

\section{Follow up instantly}

Real-time understanding of construction progress and the characteristics of traffic flow should be got to make the feasible scheme for the next step of construction.

\section{E. Follow up instantly}

Dynamic study. With the changes of construction around the block, the implementation of the road traffic space and traffic control measures to implement, traffic flow will also change corresponding. Therefore, it is necessary to do dynamic research. For example, the peak hour flow of Wuhan Second Ring Line(Fazhan Road part) fell about $10 \%$ after bridge substructure construction.

\section{F. Field service}

Traffic organization scheme designer should get involved in construction of fence and relevant transportation facilities, in order to make the $\mathrm{i}$ traffic organization scheme executable.

\section{THE RESEARCH CONTENT OF TRAFFIC ORGANIZATION DURING CONSTRUCTION}

Construction period of highways traffic organization mainly includes traffic impact analysis of the construction, construction sequence and related construction project planning, test and analysis of the overall scheme, traffic organization methods and measures, road traffic optimized design.

\section{A. Traffic impact analysis of construction}

It's required to be familiar with the general situation of the engineering and construction, grasp the regional traffic planning , and construction and to analyze the influence scope and the degree of construction.

\section{B. Construction sequence and related construction projects planning}

Sequence of construction planning means to arrange the construction sequence reasonable, to improve work efficiency and reduce the influence of traffic, referring to the requirements of the project construction process and technology, combined with road traffic conditions; related construction projects coordination is referring to the consideration of other area construction projects, following to meet the construction technology requirements, principles of neighboring project overall coordination, major traffic impact project staggered, coordinate arrangements within the region related to the construction of the project.

\section{Analysis of traffic demand forecasting}

According to regional planning situation and the arrangement, with the aid ofthe construction plan, one can use traffic prediction model to predict regional traffic demand of each construction stages, analyze and evaluate traffic and service level of regional traffic.

\section{Test and optimization of traffic organization plan}

More than one transportation organization scheme should be worked out by considering regional traffic and construction requirements, and be test by traffic forecasting model for scheme optimization.

Take Second Ring Road in Hankou section as an example. Contrast analysis of 2 schemes test result showed that during construction, full range of two-way four lanes scheme would lead to serious congestion of road construction, and also intensify Hankou central area traffic congestion, put greater impact on urban traffic than partially range of two-way four lanes scheme (the rest were two-way six lanes); the key road during construction is mainly Fuxing village to Zhuyeshan segment congestion, therefore the later scenario is recommended, with some necessary traffic control measures to be taken.

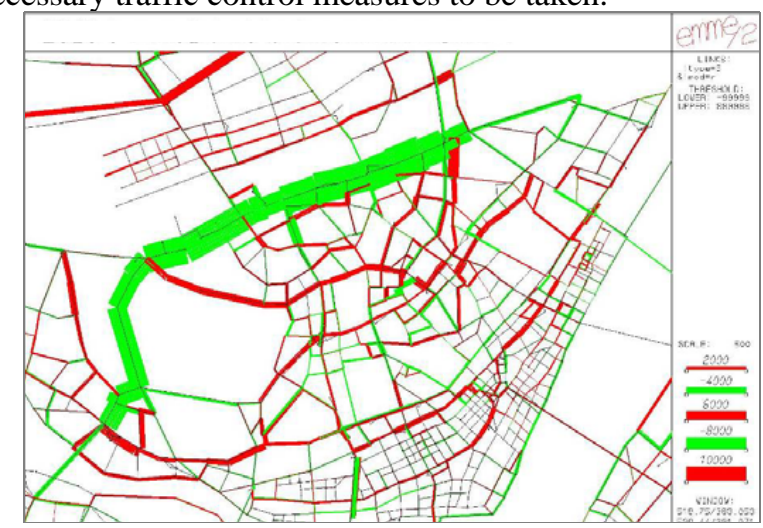

Figure II. comparative map of totally 4 lanes in construction and before

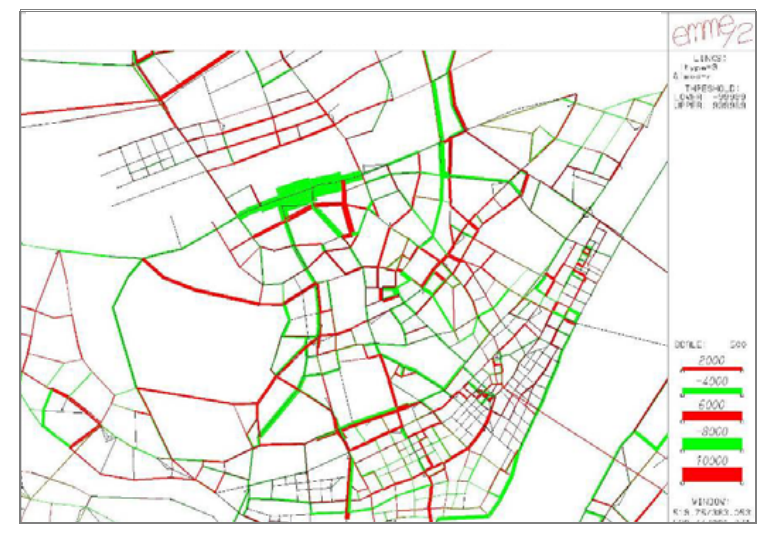

Figure III. comparative map of partly 4 lanes in construction and before

\section{E. Methods and measures of traffic organization during the construction}

On the basis of the overall scheme of the construction, we put forward the specific techniques and relevant 
measures for traffic organization during the construction period, which mainly includes regional traffic shunt (regional traffic induction, traffic control (such as restricted vehicle models, license plate, travel time and parking), transport adjustment methods.

1) Shunt path: Based on the regional road condition, one should choose the potential diversion road, including those are exist, about to be built or improved recently, then suggest the engineering measures that diversion road in the need to implement, such as speeding up the construction, widing the road, adjusting the traffic signal control or other measures to remediation.

2) Traffic control: In case that road traffic flow or lane construction is unable to meet the normal passage of vehicles under the condition, traffic control measures must be taken. Traffic control measures generally include: truck traffic limits, cars limits by license plate tail the odd and even number of traffic, a direction of the vehicle traffic restrictions and so on, that need comprehensive consideration of the road traffic volume, vehicle composition, Lane Construction and regional road network elements, which are determined through traffic model prediction and analysis.

Take Wuhan Zhiyin Bridge for example. During its construction period which was planned to be broadened from two-way four lanes to two-way six lanes, it had traffic capacity of only two lanes on condition that its peak flow has reached 4473 vehicles / hour before construction. Therefore, it is necessary to implement traffic control measures. Based on predict research, a series traffic control measures were taken, such as ban on truck and motorcycle traffic, restrict on small buses, taxis and buses by odd and even numbers of plates, thus real peak hour flow decreased to 2359 vehicles and the basic traffic were met.

3) Bus adjustment: In order to ensure the smooth progress of the construction of road construction, with the condition permits, one can shunt bus lines to ease traffic pressure on the construction road. In transport adjustment process, it's necessary to keep the transit network structure as before, and make larger adjustments to bus line network structure in principle on the wrong, reduce public travel walking distance and travel time as possible.

\section{F. Optimization design of construction road traffic}

According to the procedure of the project construction, one needs to formulate corresponding traffic organization scheme in various stages, set reasonable driveway and sidewalks, layout of the signs, and establish scientific construction methods, in order to improve the road traffic capacity.

\section{G. Evaluation of microscopic traffic simulation}

The establishment of micro simulation model for traffic analysis should be built on an important node in the road or road construction if the project research needs.

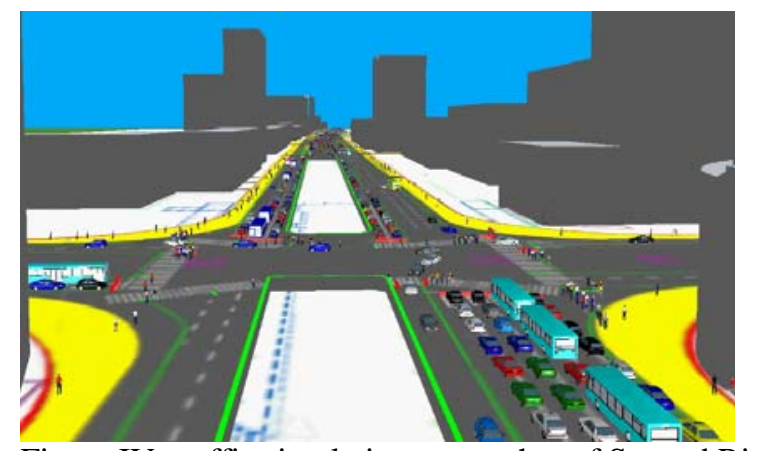

Figure IV. traffic simulation screenshot of Second Ring Line under construction

\section{STUDY ON CONSTRUCTION STAGE}

The viaduct and subway construction projects are common examples in Wuhan city.

\section{A. The viaduct construction project example}

It's usually divided into three main stages according to the sequence of viaduct construction and its impact to traffic: pipeline relocation construction period, substructure construction period, upper-structure (including ramp) construction.

1) Pipelines relocation construction period: Before pipelines reconstruction renovation, first of all, we should do a series of preparatory work such as to dismantle the green belt, fences, traffic island and pedestrian bridges, and clean other facilities on the road, and also to finish expropriation and demolition work of land-buildings within road planning red line.

To meet the requirements of the construction process, the pipelines these affect the main bridge construction must be removed, and other pipelines can be built on when the viaduct is complete and the road surface is under construction. The pipelines (diameter of 1 meter below) across the road can be constructed in undermining method, open cut and cover method or pipe jacking method to ensure the construction of road traffic in no interruption.

Pipelines relocation construction should try to maintain the existing curb stone position unchanged.

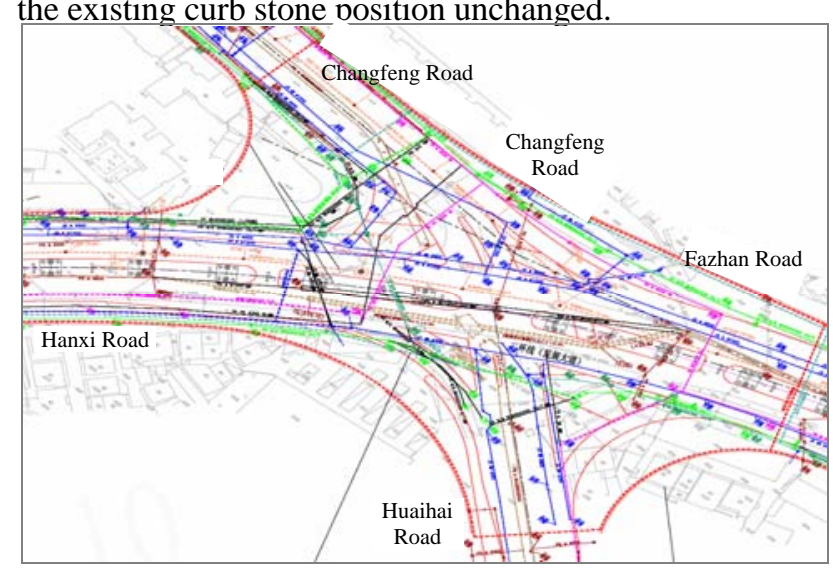

Figure V. Present Situation And Planning Layout Of Pipelines 


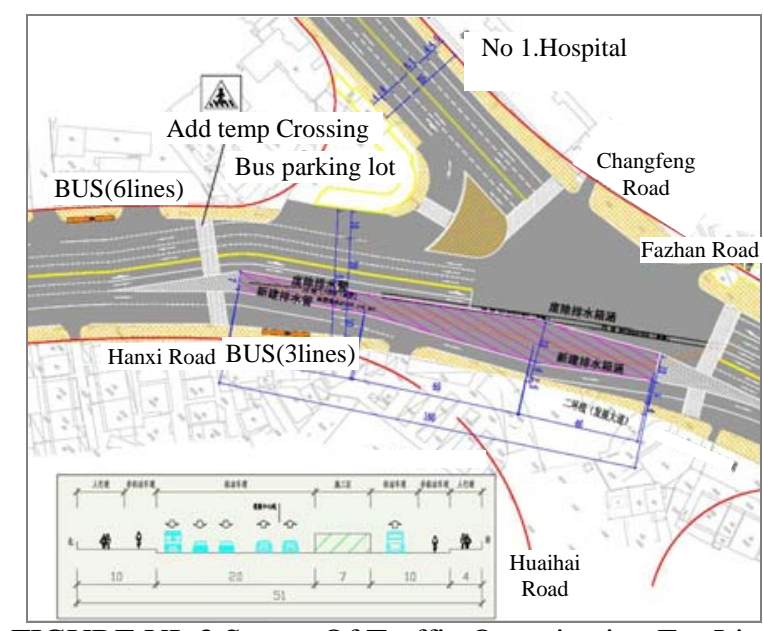

FIGURE VI. 3 Stages Of Traffic Organization For Line Relocation

2) The substructure construction period: Bridge substructure construction generally occupies road width of $10 \sim 12 \mathrm{~m}$. Through greening belt demolition on road and re-arrangement of road section, it will be able to ensure adequate traffic ca $\mathrm{BuS}_{\text {(3lines) }}$ ind the space for pedestrian and bicycle, therefore the current level of service can be maintained.

Traffic organization scheme should avoid the edge of pier formed; The position of the bus station should be adjusted according construction working face before and after; Existing road edge stone position should be kept unchanged; Particular attention needs to be paid to the protection and transformation of underground pipeline. We must arrange the traffic organization planning and construction process well, so as to shorten the construction period and reduce the impact on urban traffic.

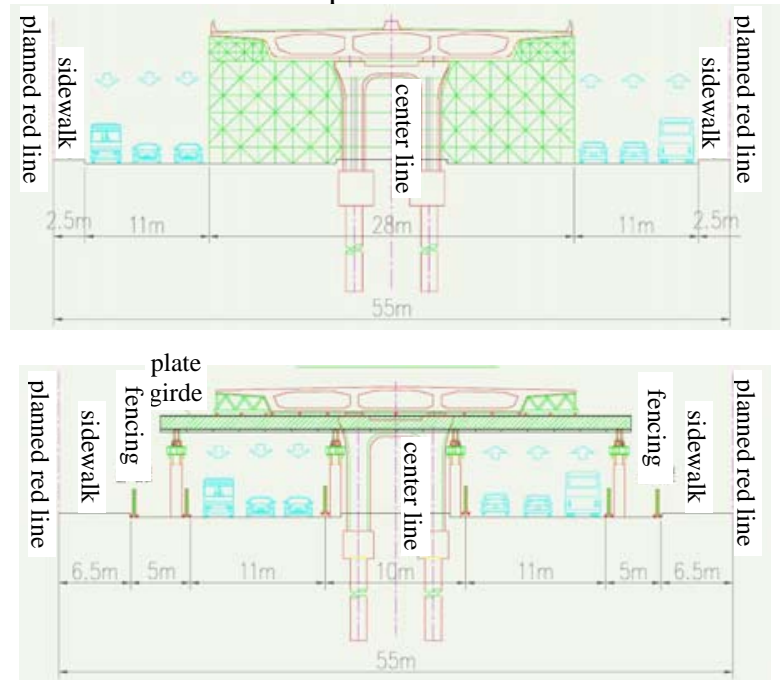

Figure VII. Full Framing Support Method (Above)And Beam Timbering Construction Support Method(Below)

3) The substructure construction period: Bridge superstructure construction period occupies the most road space and resources of three stages, so it's the period of the greatest impact on road traffic. Currently, the prevalent methodologies include full support method and beam support method. Full support method means taking support bracket (often called the scaffolding)at regular intervals with dense erection; Beam support method is a construction method of reinforced concrete beam situ irrigation in the bridge position riddled with stents or piers in assembling steel truss beam.Construction methods above each have advantages, disadvantages and adaptability, which should be chosen in specific situation flexibly for viaduct construction. The comparison of two main construction methods is shown in Fig. VII.

The main bridge and ramp construction period have to be staggered to relieve traffic congestion. General order is building the main line of the bridge first, then side by side of the ramps, which can avoid too much occupation of road space to guarantee road traffic pass.

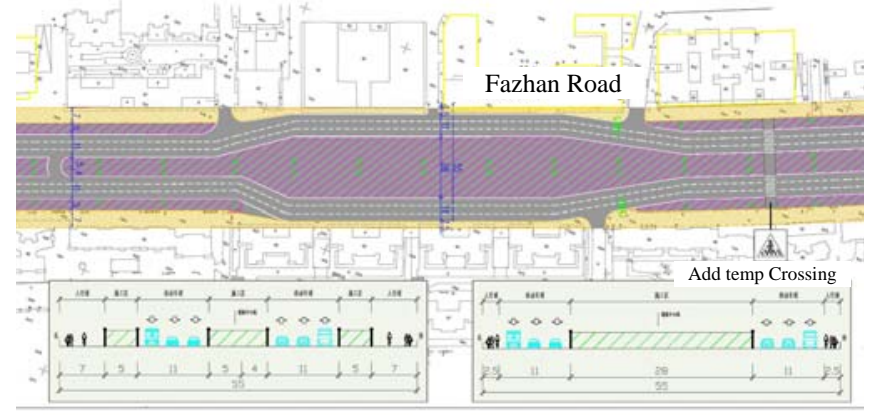

Figure VIII. main line of viaduct under construction

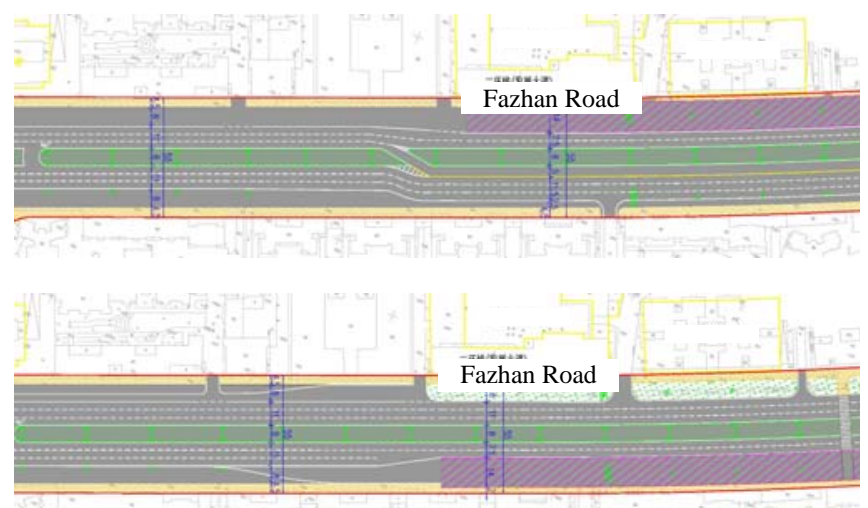

Figure IX. north(ABOVE)and south(below) ramps under construction

\section{B. Subway construction project}

The subway project construction stages division is mainly related to construction method. In the view of impact on urban traffic, subway construction methods are mainly consist of open cut method, cover cut method, subsurface excavation method, shield method, immersed tube method, the hybrid method and so on. Methods and practice of many papers on how to organize traffic reasonably during subway construction have also been discussed frequently, which is omitted here.

\section{APPLICATION EFFECT}

Wuhan Avenue construction traffic organization scheme has used the technology studied above, and traffic survey (Fig X)showed that, the peak hour traffic flow of Wuhan Avenue under construction is reduced by an 
average of about $10 \%$, which most road service level is basically maintained at $\mathrm{D} \sim \mathrm{E}$ level as before except local tension road still is $\mathrm{F}$, thus the normal operation of traffic is guaranteed during construction period; When completed, the road service level of Wuhan Avenue ground sections was generally $\mathrm{B} \sim \mathrm{C}$ level, which has greatly improved, indicates that the Wuhan Avenue is plays the role of fast ray channel in Wuhan city.
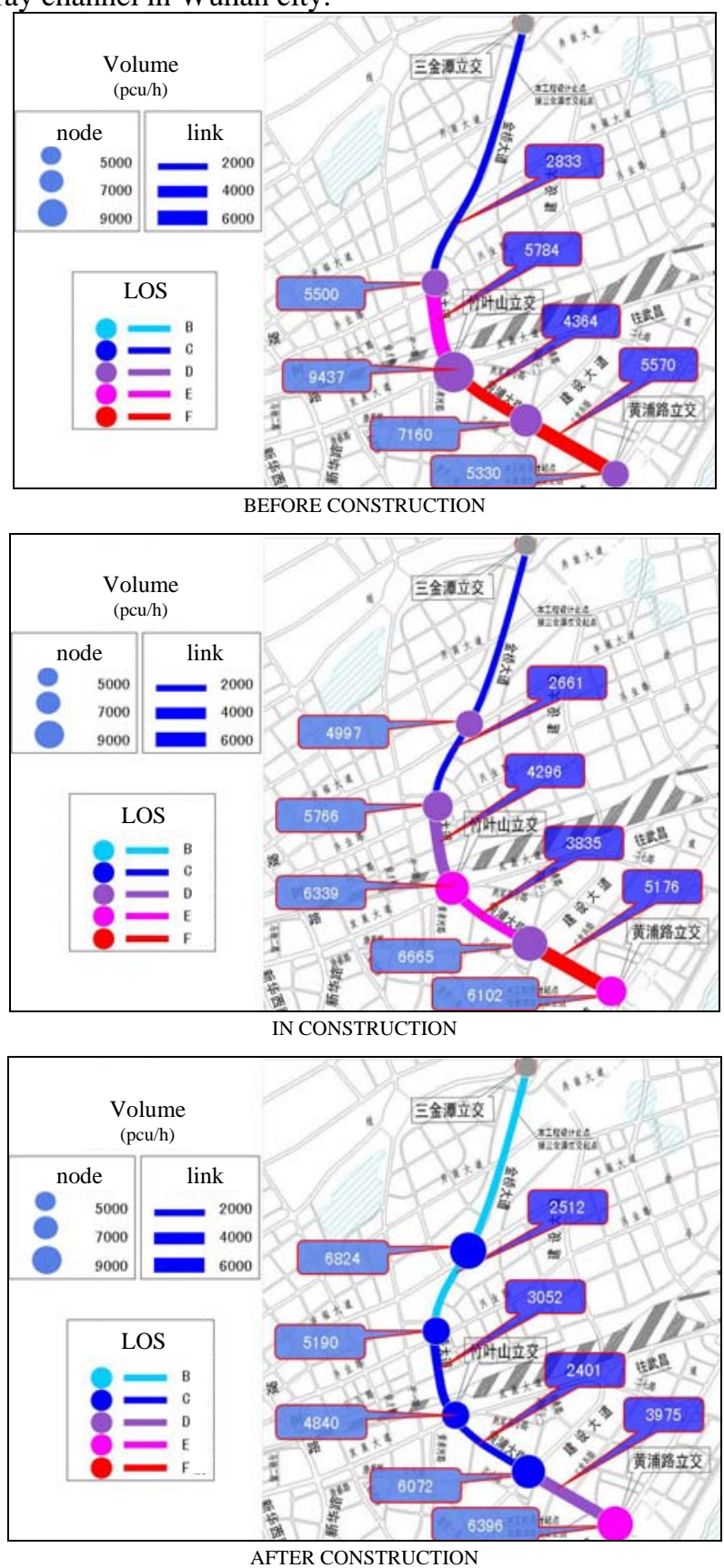

Figure X. Results of traffic volumes and service level of Wuhan Road before in and after construction

\section{CONCLUSION}

Subway and elevated bridges are typical projects construction of Wuhan City. Which have supplied valuable basis of practice and universal experience that referred to other cities. Besides basic traffic organization techniques and methods listed above, project characteristics and actual situation should be considered together in order to organize traffic well and guarantee the normal traffic operation.

\section{REFERENCES}

[1] Liu Jin, WANG Zhi-qiang etc al. Specification of traffic organization for Wuhan urban construction work(draft standard for comment)[S]. Wuhan, 2011.

[2] Specification of traffic organization for urban road work GA/T 900-2010 [J]. Beijing: BMPS, 2010.

[3] Huang Jingjuan. Study on Traffic Operation during the large-scale Municipal Construction. [D] Southwest Jiaotong University, 2008.P16-20, 48-49,.58-63

[4] Li Jianzhong, Liu Jin, She Shiying, Wang Zhiqiang etc al. Traffic organization scheme for construction period of Second Ring Road in Hankou[R]. Wuhan: WCCTPI, 2009.

[5] Yang Qing-xiang. Operative Methods for Traffic Organization during Engineering Construction[J]. Guangzhou: Journal of Guangdong Communications Polytechnic, 2008.12:18-21.

[6] Zhai Zhongmin. Traffic Control Organizations and Optimization[M]. Beijing: Beijing People's Communications Publishing House, 2004.

[7] Wu Bing. Traffic Control and Management [M]. Beijing: China Communications Press, 2005:158-161.

[8] Ma Xiao, Ding Heng, Zhang Weihua. Methods For Determining Traffic Impact Area During the Construction Period of The Road [J]. Hefei: Journal of Hefei university of technology, 2011, 34(5): 655-660.

[9] Song Liying. Traffic organization during urban road constructions. Journal of Beiijng Institute of technology ,2012.Vol.21.No.2 [J]doi:10.15918/j.jbit1004-0579.2012.02.019

[10] Wu Zufeng, Xu Yong-bing, Traffic Organization Planning During the Construction Period of the Road. Planners, 2010.No.1.Vol.26.

[11] Lei Xing. the Traffic Impact and Traffic Organization of Occuying-Road [D] Chongqing:Chongqing Jiaotong University.2012. P35-58.

[12] Ma Jing. Method on Traffic Management during the Traffic Construction of Urban Rail.[J]. Xi'an: Chang'an University.2014.P9-10. 